\title{
CANCIONES DE AMIGO «LIDIAS» EN POEMAS GRIEGOS
}

The «lydian» line inserted in Hipponax, fr. 95 Degani, together with other preserved in Hesychius, provides a "missing link» for Greek Women's songs.

Siguiendo el "rastro de caracol del alfabeto", como decía el Dr. Johnson, caemos en la cuenta de relaciones que pasarian desapercibidas por muchas veces que se releyeran ciertos textos. El tener que desentrañar para el volumen IV del $D G E$ las formas glosadas por Hesi-

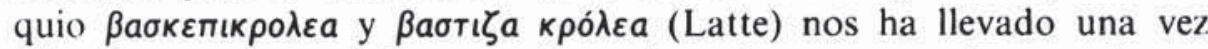
más al encuentro con las "canciones de amigo" en una de sus más curiosas facetas, el uso de lenguas extranjeras dentro de una composición mayor. Como es sabido, esta es una caracteristica de las jarchas medievales ', de las que tan interesantes testimonios se han encontrado en relación con la Peninsula Ibérica y sobre cuyos precedentes antiguos hemos publicado algunos trabajos ${ }^{2}$.

Ambas formas parecen tener elementos comunes, pero no han podi-

\footnotetext{
1 «En su preceptiva y, al mismo tiempo, florilegio de muwaššah-s, Dãr al -tirāz, compuesto hacia 1200 y dirigido a un público oriental, con harǵa-s en árabe (clásico y vulgar), en persa e incluso en beréber, nos describe Ibn Sanā' al Mulk como debia ser la harğa: ... Es ley y obligación incluso en la harğa que el poeta pase a ella bruscamente y como evasión del propio tema... y lo más a menudo se pone la harǵa en boca de jóvenes o mujeres o de una beoda o de un beodo; en tal caso, no faltará el hast que precede a la harğa, un enlace como 'él dijo' o 'yo dije' o 'él cantó' o 'yo canté o 'ella cantó... A veces la harğa está compuesta en lengua extranjera; en tal caso, es condición que estas palabras en lengua extraña sean igualmente vulgares y abrasadoras y ramadies y jergales...'” (J. M. Solá Solé, Corpus de poesia mozárabe. Las harğa-s andalusies, Barcelona s.a., pp. 26-27 (en adelante SS).

" "Poesia griega 'de amigo" y poesia arábigo española", EMERITA 40, 1972, pp. 329-396 (en adelante "Poesía griega 'de amigo"»); "La poesía griega 'de amigo' y los recientes hallazgos de Arquiloco", EMERITA 45, 1977, pp. 1-6; "Anacreonte 2 PMG y la canción sefardi 'La mar está en fortuna'», EMERITA 55, 1987, pp. 247-251. También Greek Women's Songs y 'Cantos de mujeres' y poesia 'de amigo' en la Grecia antigua (con una Antología de cantos de mujeres (= $A C M$ ) [en prensa].
} 
que pronuncia sin duda un dístico 9 en el que se mezclan palabras lidias y griegas.

Nuestra opinión es que nos encontramos ante otra más de la serie de coincidencias temáticas y formales con las jarchas hispánicas medievales que refuerzan las tesis que hemos sostenido en otras ocasiones, como decíamos al comienzo de este artículo. De ellas vamos a resaltar las siguientes:

1. La semejanza de las traducciones griegas dadas por Hesiquio con muchas de las jarchas hispánicas es muy grande por su contenido:

$S S 16^{10}$ ¡Ven a mi lado, amigo! ... ¡Ven a la unión!

SS 30 ¡Ven mi señor, ven!

SS 43 ...¡ Ven, bésame! ¡Amigo mío, ven a mi lado!...

SS 44 ... iVen, oh ven, amigo mio!...

SS 46 ...iEntrad... aqui!

2. La fórmula introductoria que anuncia a una mujer que va a hablar o cantar en lengua extranjera es un rasgo propio de la preceptiva del género «jarcha»":

SS 38b ...mientras exclamo en la lengua de Edom: «Mi corazón se va de mi...”

SS 40a una doncella... expresaba claramente en lengua extranjera cantando la privación de la belleza magnifica (del amado): «¿Qué haré o que será de mí?»

3. Aunque gran parte de las que en otras ocasiones hemos definido como 'canciones de amigo' griegas parecen evidenciar más el punto de vista de la mujer que se duele por la pérdida del amante que la solicitación amorosa, hay testimonios relativamente abundantes de coincidencias en este sentido entre dichas "canciones" y las glosas de Hesiquio:

$47 A^{12}$ (Ar., Ec. 952-5, cf. 960-3)

$\delta \varepsilon \tilde{u} \rho \circ \delta \eta, \delta \varepsilon \tilde{u} \rho \circ \delta$,

merizante en poemas "de amigo" griegos, v. ya nuestro "Poesía griega 'de amigo"», p. 363 .

${ }^{9}$ Asi puede verse en la edición de F. Rodríguez Adrados, Líricos griegos. Elegiacos y yambógrafos arcaicos, Madrid 1981, II, fr. 92.

io Diferentes formas del verbo 'venir', especialmente la segunda persona del imperativo, son frecuentísimas en las jarchas: v. SS, p. 347.

"V. n. 1. Aunque ya en "Poesia griega 'de amigo", dedicábamos unas páginas a la existencia de poesía griega bilingüe en Grecia (pp. 370-372), son los versos "greco-lidios" de Hiponacte los que con mayor exactitud cuadran con la preceptiva enunciada por Ibn Sanā' al Mulk.

${ }_{12} A C M=$ Antología de cantos de mujeres, en E. Gangutia Elícegui, 'Cantos de mujeres' y poesía 'de amigo'... (en prensa). 


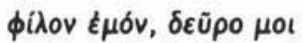

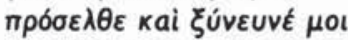

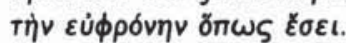
"iAquí, aqui, amado mío, aqui, a mi, a mí! ¡Entra y acuéstate conmigo mientras dure la noche!» (cf. ib. 911-3, Sapph. 48 Voigt).

En el mundo griego bizantino y en época casi contemporánea con las jarchas y su preceptiva, un autor de tradición hiponactea, Teodoro Pródromo, persistirá en el mismo género con léxico semejante y de picantes insinuaciones ${ }^{13}$ :

\section{ACM}

$\delta \varepsilon \tilde{\rho} \rho, \tau \varepsilon \chi v i т a, \delta \varepsilon \tilde{\rho} \rho$,

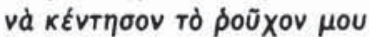

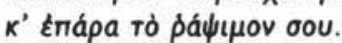

«Aqui, artesano, aqui, cose mi vestido, toma tu aguja de zurcir!»

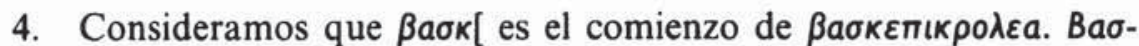

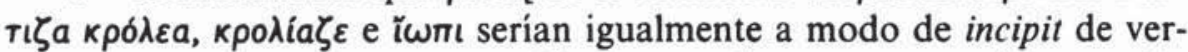
sos o versos enteros para ser utilizados en diversas composiciones, elementos prácticamente independientes cuya razón de ser sería precisamente la posibilidad de ser insertados en otras composiciones con las que suele tener poco o ningún nexo lógico. De ahí las grandes perplejidades de los críticos que encuentran el estilo «incohaerens et abruptum... et Alexandrinae potius artis argutias redolere» ${ }^{14}$. Esta aparente incoherencia se debe casi exclusivamente al convencionalismo del género

5. El segundo verso del dístico, como el resto de la composición, es notable por su obscenidad y escatologia ${ }^{15}$. Aunque tanto en las canciones locrias ${ }^{16}$ como en la preceptiva de las jarchas de Ibn Sanā' al

${ }_{13}$ D. Hesseling y U. Pernot, Poèmes prodromiques en grec vulgaire, Amsterdam 1910, IV 95; ver nuestro "Teodoro Pródromo y Ben Quzmán», Erytheia 4, 1984, p. 60 .

${ }^{14}$ K. Latte, «Hipponacteum», Hermes 64 , 1929, p. 388. Es el mismo carácter "alejandrino" que descubre D. Page, Sappho and Alcaeus, Oxford 1955, pp. 291294, al ocuparse del fr. $10 \mathrm{~A}, \mathrm{~B}$ de Alceo (4 $A C M$ ), considerado por nosotros del tipo de la 'canción de amigo'. Ver en nuestro 'Cantos de mujeres' y poesia 'de amigo' en la Grecia antigua (en prensa) los capitulos I 2: "Los poemas 'de amigo' insertos en otras composiciones en la poesia griega arcaica», y V 1: «Poesia helenistica. Los grandes poetas y poesía fragmentaria».

is «Se trata del más obsceno y repugnante pasaje de nuestro autor y, quizá, de la literatura griega", F. Rodriguez Adrados, op. cit., n. 2 a fr. 92; cf. también W. Sousa Medeiros, Hipónax de Éfeso, Coimbra 1961, fr. 64. $697 \mathrm{~b}$.

${ }^{16}$ Que consideramos un subgénero importante del 'género de amigo': ver Ath., 
Mulk ${ }^{17}$ se resalta más el carácter picante y apasionado que la obscenidad, ésta no es una rareza ni en las canciones "de amigo" griegas ni en las últimas ${ }^{18}$.

6. Mientras que los héroes homéricos se entienden desde bandos opuestos en una lengua común, o mejor dicho, la cuestión de qué lengua utilizan es irrelevante, el hecho de que una mujer domine o cante en una lengua extranjera parece ser, ya desde la épica, un atractivo adicional: ya en la Odisea IV 279 Helena es celebrada por sus conocimientos poliglotas ${ }^{19}$.

Es en los Himnos homéricos donde podemos encontrar ejemplos muy ilustrativos de este fenómeno cultural. En el Himno a Afrodita 119 es la propia diosa del amor la que hace gala de conocimiento de lenguas al requerir de amores a Anquises, presentándose como mujer frigia, pero buena conocedora de la «lengua de Troya». Las jóvenes delias del Himno a Apolo celebran a éste, a Leto y Ártemis; a continuación "entonan un himno y fascinan a las estirpes de los hombres. Las voces e incluso el chapurrear de todos los hombres saben imitarlo. Aseguraría cada uno que es el mismo el que habla. ¡Con tal fidelidad se adapta su hermoso canto!» ${ }^{20}$

El abanico de lenguas posibles abarca desde el griego en sus variados dialectos ${ }^{21}$ (cabe pensar que ésta es también convencionalmente la «lengua de Troya» en el Himno a Afrodita 113 ss.) hasta una serie de lenguas minorasiáticas: Afrodita se presenta como una doncella frigia, el licio se ha postulado para los cantos de las concellas delias ${ }^{22}$. Por nuestra parte, creemos que el lidio pudo ser una lengua cultual no griega en relación con la familia apolínea, ya que la Ártemis Efesia recibía culto en su famoso templo por parte de doncellas lidias si atendemos a los versos de Aristófanes en Nubes 595-600:

\footnotetext{
17 Ver supra, n. 1.

18 Ver $A C M$ 2, 42-45, la parodia en Supplementum Hellenisticum, n. ${ }^{\circ} 975,5$; $S S$ 48; posible escatologia en $S S 8$ (?).

${ }_{19}$ Sobre estas habilidades de Helena, v. en T. W. Allen, W. R. Halliday y E. E. Sikes, The Homeric Hymns, Oxford $1936_{2}$, ad H.Ap. 162; también dicho de Cleopatra.

${ }_{20}$ Trad. de A. Bernabé, Himnos homéricos. La Batracomiomaquia, Madrid 1978, p. 113.

${ }_{21}$ Según el comentario ad loc. en Allen-Halliday-Sikes, The Homeric Hymns cit. Creo que en esto están equivocados, aun cuando sus notas son utilisimas para nuestro trabajo.

22 Según F. Cassola, Inni omerici, Milán 1975, p. 497, los cantos de las doncellas delias serían "canti molto antichi, in lingua non greca; si pensa in particolare a l'inno del poeta licio Olen".
} 


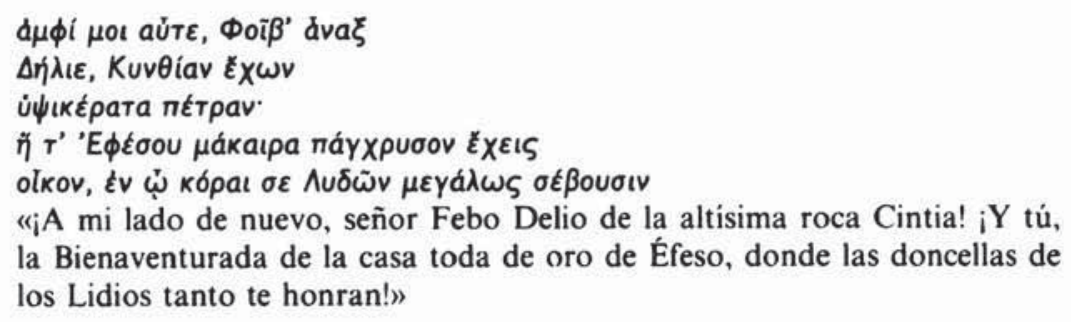

Es posible que el tipo de culto que pudieran rendir las jóvenes lidias dedicadas a la Ártemis Efesia fuera semejante al que rendian las poliglotas jóvenes delias a Apolo, Leto y Ártemis en su isla. Volvamos a la secuencia de la "suite» musical en que consiste la fiesta: una primera parte solemne, suponemos que en lengua griega, en la que se ensalza a la tríada delia y otra final en la que las doncellas del templo lucen su habilidad con cantos en lenguas extranjeras ante una concurrencia formada por no griegos que reconocen sus lenguas nativas. Este esquema nos trae a la mente el escolion de Píndaro, del que sólo se conserva el fragmento 122 (Snell), compuesto para ser cantado después de la oda (Olimpica 13), cuando las hieródulas dedicadas a Afrodita sacrificaban junto con el propio oferente, Jenofonte de Corinto. Aunque sobre las doncellas delias no se cierna ninguna sospecha, hay quien ha visto en los cultos lidios en Éfeso «une trace» ${ }^{23}$ de 'prostitución sagrada' o, más bien, diriamos, de las costumbres lidias femeninas que en cierto momento resultaron escandalosas para los antiguos. Nuestra opinión es que pudo efectivamente darse este fenómeno, dirigido casi exclusivamente a extranjeros ${ }^{24}$, en los diferentes templos: "une trace» de lo cual consistiria en escandalosas 'canciones de amor' que habrían llegado a obrar como sacrificio sustitutorio de la prostitución institucional: sería el mismo caso de las doncellas y canciones locrias tal como lo tratamos en 'Cantos de mujeres' y poesía 'de amigo' en la Grecia antigua 25 .

Un resto a niveles aparentemente más personales sería la "canción de amigo' lidia contenida en el poema hiponacteo; recordemos que casi desde su publicación se ha visto en esta composición el remedio paródico hasta el ridiculo de un rito ${ }^{26}$. El verso «lidio» o en jerga «lidio-frigia" sería una canción bien conocida en la ciudad natal de Hiponacte, Éfeso, junto con otras similares, existiendo ya la posibilidad de que pu-

${ }^{23}$ Ch. Picard, Ephèse et Claros, París 1982, p. 233.

24 Como puede verse ya desde Hdt., I 199.

${ }^{25}$ Cap. III 3, "Las 'canciones locrias' en el marco de su sociedad e instituciones", donde apuntamos la relación con instituciones lidias semejantes.

26 V. las referencias en Degani, op. cit. 
diera ser integrada por un poeta en su propia producción, de acuerdo con ciertas convenciones. Algún curioso recogería los restos de este "cancionero lidio" ${ }^{27}$ que, junto con tantas otras cosas, fue a parar al léxico de Hesiquio.

El pequeño fragmento "lidio" conservado en Hiponacte es en sí un auténtico 'eslabón pérdido' del género de los 'cantos de mujeres' griegos cuyas variadas facetas hemos estudiado con el resultado de su escasa divergencia con la preceptiva de las jarchas tal como la describe Ibn Sanā' al Mulk.

Tras los antiguos testimonios babilonios ${ }^{28}$ el eslabón «lidio» o minorasiático es fundamental para la difusión en el mundo de las colonias griegas de Asia Menor de este género en el que se identificaba, ya en el s. IV/III a.C., a Safo, Anacreonte y las "canciones locrias» ${ }^{29}$. De la misma manera eran vistas como canciones jonias por Aristófanes en $E c .890^{30}$, una vez destruido el mundo lidio que tanta influencia tenía sobre las colonias jonias o sobre Mitilene, tal como puede advertirse en Safo, una de las, lógicamente, grandes maestras del género. El carácter dialingüístico de la canción de amor en boca de mujer hará que sobreviva a los más variados géneros con una vitalidad sólo comparable a la de las fábulas ${ }^{31}$.

Elvira Gangutia Elícegui

${ }^{27}$ Algo parecido al n. 286 de D. Page, Supplementum lyricis graecis, Oxford 1974, en el que se han detectado posibles incipit atribuibles a Safo o a Anacreonte; alguno de ellos es posiblemente el comienzo de una canción 'de amigo": (28 ACM

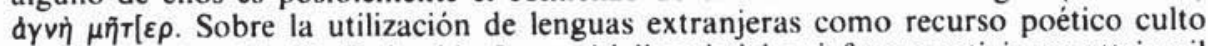
en Hiponacte, vid. G. Tedeschi «I prestiti linguistici nei frammenti ipponattei e il problema dellinterferenza culturale ad Efeso", Quaderni di Filologia Classica 3. 1981, pp. 37-48.

${ }_{2 \times}$ Donde "se trata de una pieza peculiar y única en la literatura acadia de la época del babilonio antiguo", n. 151 del traductor E. Martinez Borobio a 1 ACM en nuestro 'Cantos de mujeres' y poesia 'de amigo' en la Grecia antigua, en prensa.

${ }^{29}$ Clearco, fr. 33 (Ath., 638e-639a).

30 Glosadas algo más abajo con alusiones obscenas a costumbres jonias y lesbias

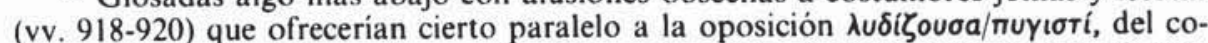
mienzo del poema hiponacteo que venimos estudiando. Aunque las canciones fueran ya «jonias", las melodias pudieron seguir siendo «lidias" o "frigias», incluso anotadas cuidadosamente en forma interlinear en los manuscritos. Aunque burlesco, cf.

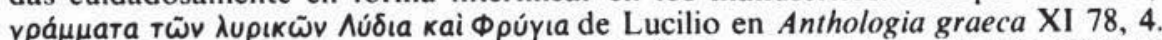

${ }_{31}$ F. Rodriguez Adrados, Historia de la fábula greco-latina, Madrid 1979-1987, tres vols. 